\title{
MULHERES TRANS, VIOLÊNCIA SIMBÓLICA E O RITO DE PASSAGEM DE INDIVÍDUO A SUJEITO TRANS NA PERSPECTIVA DE ALAN TOURAINE
}

TRANS WOMEN, SYMBOLIC VIOLENCE, AND THE RITE OF PASSAGE OF THE INDIVIDUAL TO THE TRANS SUBJECT IN THE PERSPECTIVE OF ALAN TOURAINE

\author{
Juliani Borchardt da Silva
}

Universidade Federal de Pelotas, Pelotas, RS, Brasil. E-mail: juossette@hotmail.com

\section{Lucimary Leiria Fraga}

Universidade Federal da Fronteira Sul, Cerro Largo, RS, Brasil. E-mail: lucimary23@hotmail.com

\section{Sandra Vidal Nogueira}

Universidade Federal da Fronteira Sul, Cerro Largo, RS, Brasil. E-mail: sandra.nogueira@uffs.edu.br

\section{Serli Genz Bölter}

Universidade Federal da Fronteira Sul, Cerro Largo, RS, Brasil. E-mail: serli.bolter@uffs.edu.br

DOI: https://doi.org/10.46550/ilustracao.v2i1.62

Recebido em: 06.04.2021

Aceito em: 29.04.2021

\begin{abstract}
Resumo: Neste artigo abordam-se conexões entre violência simbólica, sujeito e transfeminismo como práxis emancipatória. A pergunta que norteia esta investigação é: a passagem de indivíduo a sujeito pode inibir a violência simbólica contra o segmento trans? Assim, num primeiro momento seráo feitas consideraçốes acerca da violência simbólica como forma de opressão as identidades trans. Num segundo momento, será abordada a busca por cidadania como uma afirmação do direito à diferença. Em seguida será discutida a definição do ser mulher e a constituição das transidentidades enquanto sujeitos, a partir de Alain Touraine. Por fim, é discutido o sujeito trans no movimento transfeminista e sua importância para a garantia dos direitos trans. Em nível metodológico, faz-se uma abordagem histórico-sociológica para compreender os aspectos sociológicos que envolvem o processo do tornar-se sujeito e cidadão, além de possibilitar um olhar sobre a violência simbólica sofrida por este segmento. A compreensão complexa mostra-se pertinente, a fim de possibilitar um olhar sistêmico para as vivências Trans, tirando-as da (in) visibilidade social.
\end{abstract}

Palavras-chave: Trans. Violência simbólica. Indivíduo. Sujeito em Alan Touraine.

Abstract: In this article connections between symbolic violence, subject and transfeminism as emancipatory praxis are addressed. The question that guides this investigation is if the passage from individual to subject can inhibit symbolic violence against the trans segment? Thus, at first, considerations will be made about symbolic violence as a form of oppression of trans identities. In a second moment, the search for citizenship will be approached as an affirmation of the right to difference. Next, the definition 
of being a woman and the constitution of transidentities as subjects will be discussed, based on Alain Touraine. Finally, the trans subject in the transfeminist movement and its importance for the guarantee of trans rights are discussed. At the methodological level, a historical-sociological approach is taken to understand the sociological aspects surrounding the process of becoming subject and citizen, besides allowing a look at the symbolic violence suffered by this group. The complex understanding proves to be pertinent in order to enable a systemic look at the Trans experiences, taking them out of (in) social visibility.

Keywords: Trans. Symbolic violence. Individual. Subject in Alan Touraine.

\section{Introduçáo}

A s temáticas envolvendo sexualidades, desejos e vivências de seres humanos que se auto Lidentificam gênero-divergentes ${ }^{1}$ sempre acaloram as reflexôes no meio acadêmico. No mesmo compasso, quando abordadas fora deste espaço, em muitos momentos são carregadas de tentativas disciplinadoras e morais, ou, de forma ainda mais retrógrada, são trazidas à tona pelo caráter meramente biológico. Todavia, tais reflexóes necessitam mergulhar na seara dos direitos humanos, da liberdade de expressão, da alteridade e da não castração ao desejo e aos corpos Trans.

Há que se transcender da abordagem patologizante e biológica quando se falar em Trans e homossexuais, compreendendo que a construção da sociedade se perfaz cada dia mais plural, não cabendo mais análises que não contemplem a multiplicidade de diferenças sociais construídas a partir de vivências e historicidades de cada ser humano ao longo da vida. Sendo assim, este ensaio reflete acerca do universo Trans, perpassando temas como violência simbólica, cidadania e diferença buscando entrelaçar tais debates com a perspectiva de indivíduo, sujeito e ator social em Alan Touraine. Por fim, busca compreender como os Movimentos Sociais, especificamente o Transfeminismo pode emancipar homens e mulheres Trans na busca pelo reconhecimento e pela cidadania, ou, ao menos, dar-lhes ferramentas para percorrer este caminho.

\section{Breves consideraçóes acerca da violência simbólica}

Ao se analisar a violência na sociedade, parte-se da premissa de não a compreender de forma simplória, imaginando que ela só se manifeste na forma física, pois suas facetas são inúmeras nas relaçôes sociais. Conforme relembra Calderone "pensar la idea de violencia simbólica implica pensar, necesariamente, el fenómeno de la dominación en las relaciones sociales, especialmente su eficacia, su modo de funcionamiento, el fundamento que la hace posible. (CALDERONE, 2004, p. 1).".

Neste compasso, seguindo o mesmo entendimento de Calderone, em sua obra "Topologia da violência” o autor Byung-Chul Han preleciona que em diversas oportunidades a violência se encontra no cerne do sistema social, ou, ainda, no contexto sistêmico em que este se encontra. (HAN, 2017, p. 161). No mesmo caminhar, Bourdieu ao abordar a teoria do habitus, refere que os indivíduos ao adquirirem comportamentos habituado-repetitivos, por meio do inconsciente,

1 No entender da autora Letícia Lanz, gênero-divergentes são aqueles seres humanos que destoam das normas binárias de gênero (macho/fêmea), deste modo, o termo abarca todas as identidades que não se enquadram neste padrão. (LANZ, 2017). 
podem sofrer formas de violência sem necessariamente compreenderem-nas como tal, ou, ainda, naturalizando-as.

Com isso, se observa que, inúmera vezes, pela ausência do caráter físico da violência, é na forma silenciosa que ela se enraíza na sociedade, onde o poder por meio de diversos contextos, passa a dominar indivíduos e grupos, o que pode ser considerado como meio de dominação (HAN, 2017, p. 162).

Assim, resta evidente que a violência, e, mais ainda, a simbólica, passa a anular a subjetividade e a alteridade nos indivíduos, o que muito se assemelha ao que Axel Honneth entende por reificação, ou seja, o processo de objetificação e coisificação dos sujeitos, processos que impedem o ser humano de sentir-se "ele mesmo", anulando aquilo que o diferencia dos demais. A reificação se dá de forma tão violenta, que o próprio indivíduo é capaz de se objetificar, seja pelo viés de seu trabalho, ou do próprio corpo (HONNETH, 2018).

Destarte, embora nas análises de Lukács a reificação tenha se dado direcionada ao caráter capitalista, em razão do período histórico de suas escritas, ela pode ser vista nas práticas cotidianas de diversas formas, nos momentos onde um ser humano vê o outro como mero objeto, ao passo que não o reconhece como sujeito. Desta forma, o observador não percebe o mundo, e quem está a sua volta como ser humano digno de direitos e cidadania (HONNETH, 2018, p. 86-87).

Por sua vez, Han defende que todas as espécies de violência e de não reconhecimento do outro, derivam do poder e da dominação, e tais processos atingem a sociedade, ainda que alguns indivíduos não possuam tal entendimento, e acabam soterrados pelas variadas formas de coerção social. Neste sentido, seja a violência em sua forma sistêmica, física ou simbólica, ela alimenta os sistemas de poder na sociedade, passando a figurar com um sistema de engessamento, englobando os indivíduos em teias de regras e normas como "presos" do sistema dominante, e por consequência, privados de suas subjetividades e desejos (HAN, 2017, p. 168).

Diz-se, com isso, que a violência simbólica possui tamanha perspicácia e potência, que écapaz de engessar a sociedade e os corpos sem o uso da força (em sua forma física), na medida em que a mera junção entre sociedade e sistema ressignificam práticas dominantes no decorrer da história, por meio de sistemas simbólicos de dominação, os quais em sua maioria são excludentes e negatórios de reconhecimento, de modo que o poder, ainda que de forma invisível, é extremamente eficiente, e têm produzido inúmeras situações de segregação social. Logo, no processo de análise da reificação, Honnet refere que esta deve ser analisada também nas formas cotidianas, mas, igualmente, como economicamente utilizável nas relaçôes sociais (HONNETH, 2018, p. 11).

Na mesma seara da violência simbólica, portanto, os valores morais e culturais ultrapassados, fomentam situaçóes discriminatórias, na medida em que estipulam padrôes a serem seguidos para as vivências na sociedade, reduzindo os corpos a condição de meros objetos imersos em um sistema de anulação dos corpos, das sexualidades, da religiosidade, e de outras escolhas possíveis pelos indivíduos. É neste emaranhado de relações que a violência simbólica toma forma e é reproduzida no contexto sociocultural, o que acarreta na necessidade de uma profunda reflexão acerca de tais práticas, a fim de se caminhar para um modelo de sociedade que não fomente tais situaçôes, tampouco reproduza formas de dominação que busquem objetificar alguns sujeitos e grupos em prol do bem-estar social e moral de outros, contexto em que se inserem as mulheres Trans, as quais muitas vezes são marginalizadas e invisíveis diante de situações de objetificação e negação de suas identidades. 
Afinal, esta dominação, e por consequência, uma castraçáo poda de forma violenta desejos e vivências, surgindo muitas vezes como uma "falta de algo", neste caso, a falta de uma vida com cidadania, liberdade e autonomia. (WARAT, 2004, p. 63). A castração, assim, anula as formas de expressão cotidiana, mirando nas mulheres Trans, as quais se sentem presas a padróes que não desejam obedecer, o que confirma o poder da castração, seja ela simbólica ou palpável, uma vez que este processo engole identidades e vontades em nome daquilo que não á aceito culturalmente. A castração, portanto, "é uma armadilha preparada ao desejo, pelo pavor ao distinto, a tudo que não é conjuntamente verossímil [...].”. (WARAT, 2004, p. 63). O que se busca romper, enfim, são as amarras que pretendem incansavelmente excluir a mulheres Trans dos espaços sociais, por meio de uma gênese de dominação, se buscando, em contrapartida a eliminação de uma unidade identitária que não mais tem espaço na sociedade atual, a qual é visivelmente plural, mas que insiste em se manter como ideal.

Por meio desta mudança de perspectiva em relação às mulheres Trans, e ao diferente como um todo, acredita-se que por meio do "vazio erótico" que nos impulsiona a despojar-nos de todas as couraças, dogmas e vaidades que nos levam ao imobilismo"n , seja possível que, quem diverge dos padrôes ora referidos, passe a vislumbrar uma vida com maior liberdade no que concerne ao campo identitário e subjetivo. Defende-se o vazio erótico em razão de que, como preleciona Warat, este nos possibilita enxergar e sentir coisas outras que não nossos dogmas, na medida em que não mais há uma prisão àquilo que estava posto, e sim uma abertura para o que pode ser modificado.

\section{$3 \mathrm{~A}$ busca por cidadania em meio à diferença}

Em suas escritas, Bertaso pontua de maneira acentuada, que a sociedade complexa e multicultural é realidade fática, e que a multiplicidade de cores e identidades nela existente tende a seguir crescendo (o que deve ser visto como positivo). Na sociedade multicultural, portanto, podem e devem ser fomentados processos de reivindicação ou reconhecimento de diferenças existentes entre os seres humanos, os quais buscam, de forma individual, inseriremse nos processos socioculturais (SANTOS, LUCAS, GHISLENI, 2019, p. 72). Juntamente com esta vasta composição plural, surge então, a diferença como traço significativo deste novo modelo de sociedade, onde o autor enfatiza a importância da cidadania, do reconhecimento, e da fraternidade social com base para se mudar as perspectivas sociais (BERTASO, 2012, p. 15).

Deste modo, pensar em cidadania na sociedade complexa e multicultural, requer uma compreensão de que sua concretização se dará na medida em que as relaçôes coletivas alimentarem um viés de alteridade, onde o diferente seja visto como parte do todo, só assim se firma, por meio da cidadania, um compromisso com a dignidade humana (BERTASO, 2015, p. 15), se percebendo, de forma positiva, formas de emancipação dos sujeitos e um reconhecimento individual de cada um que busca a cidadania, reivindicando neste processo, dentre outras coisas, sua identidade, e se entendendo como ser único e portador de direitos, dentre eles a cidadania, a qual possui múltiplas nuances. Neste compasso, Bertaso defende que:

Ao pensar em sociedades de extremas desigualdades, como a nossa, antecipo um primeiro manifesto: uma ideia de cidadania que desde logo período legitima o controle social àqueles grupos dotados de poder e força, que seleciona, classifica

2 (WARAT, 2004, p. 65). 
e controla a conduta dos segmentos mais fragilizados, está perdendo seu sentido e sua força de controle diante da complexidade e da proporção numérica dos "desviantes". [...] o contingente de desviantes aumenta na proporção em que aumentam os marginalizados e esquecidos da cota pessoal, que estáo à mercê da riqueza produzida. (BERTASO, 2012, p. 16).

Resta evidente que Bertaso compreende a mudança social pelo viés da sensibilidade, e para tal, a sociedade deve se sustentar, reconhecendo as diferenças e a pluralidade que a compóem, sendo justamente esta multiplicidade que alimenta a cartografia cultural e humana, e que enriquece os espaços e as relaçóes (BERTASO, 2012, p. 16). Com isso, se observa que a alteridade necessita ser fomentada em todos os espaços de convivência, na medida em que a diversidade se faz presente em todos os contextos humanos, o que sinaliza para a urgência na criação de mecanismos que possibilitem a todos os indivíduos o acesso aos diversos campos sociais sem a privação de suas subjetividades e diferenças, o que está diretamente ligado à vida digna. Ainda acerca deste entendimento, o autor pontua:

A cidadania tende a ser entendida como um locus de vincularidades, de respeito, de proteçáo e de cuidados mútuos. Uma sociedade que sobrevive de políticas sociais doadas, por uma classe política de profissionais, não viabiliza a formação de cidadania, mas a manipulação e a submissão do sujeito. (BERTASO, 2012, p. 16).

Por estas razóes, a cidadania tomou a proporção de um processo em constante evolução e emancipação, tecendo fortes vínculos com os direitos humanos, eis que ambos firmaram o compromisso com a dignidade humana, o que a torna um traço buscado nas práticas socioculturais que visam o respeito ao diferente, açôes que são próprias da aceitação da pluralidade evidenciada na sociedade complexa. De modo que "a cidadania com vínculos nos direitos humanos não se vê restrita ao exercício do voto, à nacionalidade, ou à prestaçâo obrigatória de alguns serviços, tais como o serviço militar ou eleitoral, entre outros." (BERTASO, 2015, p. 17).

Neste sentido, aqueles que não obedecem à normas impostas, essencialmente no que tange ao campo identitário e sexual, transitam em um limbo social, figurando como meros indivíduos, e náo como sujeitos ou atores, diante dos fenômenos sociais, tal qual ocorre com as mulheres Trans, e com diversas minorias, as quais em diversos locais, são figuras simbólicas de representaçáo, náo exercendo em plenitude, o ideal de cidadania.

Em semelhante perspectiva, e buscando romper com realidades de exclusão e castração, por seu turno, Warat defende a ideia da construção urgente do futurivel $^{3}$, termo que defende a possível construção de uma nova realidade social, tendo como questionamento central: que futuro está a nos esperar no que tange às subjetividades e desejos?

Com isso, pelo futurivel, questiona-se - sem esperar repostas engessadas, e sim buscando perspectivas para um futuro plural a ser construído - o afastamento de valores e padróes historicamente impostos, escapando de qualquer fronteira castradora de pensamentos, vivências e desejos. Mais que isso, o futurível é o compromisso umbilicalmente ligado com um amanhã a ser conquistado, e que deve ter o amor como premissa, o qual nos constitui como sujeitos, e como parte do todo (WARAT, 2004, p. 369-370).

Com isso se defende que os direitos humanos não mais se vistam de terno e gravata, hierarquizando-se, e ignorando aqueles que ainda náo tiveram acesso a uma vida e liberdade e

3 Ao abordar o futurível, o autor relembra as palavras de Bunge. (WARAT, 2004, p. 369). 
dignidade, na medida em que esta estrutura simbólica de exclusão, necessita urgentemente ser ressignificada (SÁNCHEZ, 2014, p. 29). Neste contexto, os direitos humanos, a visibilidade e o respeito às diferenças, devem se dar a partir do futurivel Waratiano, buscando alternativas que fujam de determinismos e castraçôes de desejos, e se entrelacem à novas formas de se viver em sociedade, onde todos sejam dignos de reconhecimento e respeito, ainda que suas características o diferenciem dos grupos dominantes.

\section{$4 \mathrm{O}$ "ser" mulher e o rito de passagem de indivíduo à sujeito trans na perspectiva de Alan Touraine}

O que é ser mulher? O que ou quem determina quem tem o direito de assim se reconhecer e transitar na sociedade?

Segundo o entender de Beauvoir, muitas foram às formas de identificar o que de fato definia uma mulher ao longo da história. Neste viés, a autora refere que, por lentes simplórias de análise, a mulher chegou a ser caracterizada meramente pelo caráter biológico, ou seja, era definida meramente como "fêmea", o que, de maneira muito redutiva, engessou-a por vasto tempo ao caráter biológico e sexual, como se a figura de um óvulo fosse capaz de definir uma mulher em sua plenitude. (BEAUVOIR, 2009, p. 35).

Neste caminhar estanque no que se refere à caracterização da mulher, a autora afirma que o mundo e/ou a sociedade, sempre foram apropriadas pelos "machos", os quais sempre buscaram dominar as "fêmeas" em diversas searas, desde o mundo animal às relaçóes humanas. Por outro lado, pelo viés da psicanálise, Beauvoir afirma que:

A fêmea é uma mulher na medida em que se sente como tal. Há dados biológicos essenciais e que não pertencem à situação vivida. ]...[ não é a natureza que define a mulher: esta é que se define retomando a natureza em sua afetividade. (BEAUVOIR, 2009, p. 71).

Diante deste olhar estereotipado em relação as mulheres, seja pelo caráter biológico, ou por outras formas de dominação existentes, Touraine, compreendendo a importância das lutas feministas na emancipação feminina, aduz que tais lutas buscavam contrapor a ideia de uma natureza feminina de caráter meramente biológico, o que ensejava diversas formas de dominação e inferioridade. (TOURAINE, 2011, p. 15).

Neste contexto, o autor refere que, muito embora as mulheres tenham conquistado direito e avançado em alguns campos, dentre eles maior espaço no mercado de trabalho, parte da sociedade, ainda as visualiza muito presas à ideia de um mundo feminino criada historicamente, em especial os homens, no intuito da formação dos papéis de gênero, o qual ao longo do tempo lançou a binaridade como centro da sociedade (TOURAINE, 2011, p. 41). E, a ideia de sujeitos binários, quando segue engessada em antigos padróes de análise, não se abre para as discussões de gênero, identidade e pluralidade dos sujeitos, tornando-os fadados a uma vida oculta, ou, ainda, invisível.

Desse modo, para além da imagem histórica acerca do "ser mulher" os corpos femininos se tornaram objeto de estudo das mais variadas áreas do conhecimento, de modo que tais reflexôes, passaram a analisar todos os lados destes corpos de forma objetiva e subjetiva, retirando muitas vezes das mulheres, a capacidade de interpretação dos próprios corpos, com isso, muitas análises em relação ao corpo feminino o apartaram dos múltiplos contextos em que as mulheres 
estáo imersas na sociedade, como se a história e os corpos pudessem ser separados (LUCAS; GHISLENI, 2019, p. 95).

Em outras palavras, historicamente, se criaram modelos de verdades e regras que de forma cruel acabaram por sufocar as possibilidades dos corpos femininos de expressarem-se em plenitude, vivendo e sentindo aquilo que desejam (SANTOS; LUCAS; GHISLENI, 2019, p. 129), e esta castração adentra, de forma consistente, na seara dos corpos Trans, os quais incessantemente resistem, necessitando reafirmar a todo o momento que são "mulheres."

Rumando, portanto, ao universo Trans, cabe salientar que mulheres e homens Trans são pessoas que não desejam viver de acordo com o sexo biológico, todavia, ainda que, nem sempre busquem alterá-lo por meio de procedimentos cirúrgicos, de modo que, ao contrário do imaginário do senso comum, a genitália não é o principal foco, sequer das mulheres e homens Trans, então, igualmente não deveria ser para critérios de análise de quem não se reconhece desta forma. Um dos principais pontos deste universo, é justamente a experiência negação do direito à sexualidade plena, ao ir e vir com segurança e respeito, logo, qualquer análise que fomente este estereótipo biológico, prejudica a luta por respeito e liberdade Trans.

Neste sentido, Santos, Lucas e Ghisleni, baseados no pensar de Burrillo acreditam que "no labirinto das possibilidades que a sexualidade humana oferece, existem aqueles que encontram nela uma fonte de prazer, outros que a renunciam." (BURRILLO apud SANTOS; LUCAS; GHISLENI, 2019, p. 129). " Sendo neste universo das castraçóes sexuais e identitárias, que estão inseridas as identidades que contrariam as normas de gênero socialmente estabelecidas (lógica binária). Em sendo assim, é essa constante transgressão das normas de gênero que identifica a mulher Trans na sociedade, o que não deixa de ser uma forma de ousar, de transcender um sistema de hierarquização dos sujeitos há muito tempo existente. (LANZ, 2017, p. 69).Sob esse enfoque, na visão de Martins:

Colocadas, geralmente, na miscelânea do termo trans ou transgêneros, as identidades transexuais e travestis se confundem em diversos discursos. A transgeneridade é a percepção que um indivíduo tem sobre a sua identidade de gênero, considerando aqui a binaridade de gêneros, na qual acompanha o sentimento de pertença a um gênero diferente do que aquele que seria o ideal pela lógica do sexo biológico. [...]. Nas pessoas trans, há uma complicação entre a percepção social do corpo e a percepção biológico-anatômica do elemento sexual identitário. (MARTINS, 2016, p. 34).

No Brasil, muito embora exista uma infinidade de homens e mulheres Trans e/ou gênero divergentes, as identidades mais conhecidas ainda são as travestis ou transexuais, eis que os movimentos sociais usualmente assim as denominam. Muitos destes indivíduos, deste modo, ainda resistem na adoção da nomenclatura "Trans" como uma espécie de guarda-chuva que abarque todas as transidentidades, seja pela influência dos $\mathrm{MS}^{4}$, ou por desconhecimento acerca dos significados destes termos.

Outra resistência neste sentido está no corte identitário existente na sociedade quanto a travestis e transexuais, o qual se dá na ordem econômica e cultural, onde a mulher financeiramente vulnerável é denominada travesti, enquanto aquela que tem acesso a bens, espaços e serviços, ou que possui status social, é chamada de transexual. Dito isso, importa salientar que toda mulher que assim se define (Trans) deve ser respeitada como tal, independentemente do caráter genital,

$4 \quad$ Leia-se Movimentos Sociais. 
da classe social e de demais características que sejam apenas excludentes.

Estas situações vexatórias de violência e segregação a que são submetidas mulheres Trans, que vão desde o não uso do nome social à homicídios (no Brasil só no corrente ano já são 96 homicídios tendo como motivação a "figura" Trans) $)^{5}$ estão muito atreladas a heteronormatividade ${ }^{6}$, eis que, ao longo do tempo, a heterossexualidade se apresenta como norma correta, impossibilitando os modos de vida diversos dos definidos biologicamente (BENTO, 2008, p. 51).

Tais imposições retrógradas acabam por influenciar o retrocesso social no sentido de não abarcar as múltiplas identidades existentes, de modo a invisibilizá-las, bem como, impedem uma maior reflexão acerca da construção identitária desses sujeitos, análise fundamental em uma sociedade plural.

Deste modo, mulher Trans aqui abordada, é a mulher divergente do padrão binário de gênero, não cabendo, portanto, análises baseadas em patologias ou perversóes, o que cultural e historicamente é reproduzido, mantendo o diferente à margem da sociedade. Tampouco se reduz à orientação sexual, mas trata-se de uma construção de cada indivíduo que assim se reconhece e deseja viver (JESUS, 2012, p. 7). Neste caminhar, questiona-se: Em relaçáo às mulheres Trans, como se perpassa do status de indivíduo a sujeito e ator na perspectiva de Alan Touraine?

Em um primeiro momento, se faz necessário compreender que, para o autor ora referido, existe uma diferença significativa entre indivíduo, sujeito e ator, de modo que ser sujeito, não significa ser ator, bem como, muitos são os indivíduos que não se tornam a atores, eis que não modificam o meio em que vivem se forma consistente, em outras palavras, não ousam modificar o que está naturalizado na sociedade. No entender de Veronese e Lacerda,

a relação existente entre esses dois aspectos, sujeito e indivíduo, apresenta-se como processo complexo de co-dependência. Dessa forma, não é possível pensar, ou mesmo teoricamente almejar, uma sociedade de plenos sujeitos. Podemos dizer que o indivíduo representa uma plataforma de manifestação do sujeito, assim como o sujeito garante maior ou menor espaço de atuação do indivíduo. (VERONESE; LACERDA, 2011, p. 422).

Já no entender de Touraine, "sujeito é vazio é o olhar sobre o corpo individual, não-social, apenas vivo e sexuado." (TOURAINE, 2004, p. 34). Desse modo, o sujeito na percepção do autor evoca uma espécie de consciência de si, e estaria no íntimo de cada ser humano, podendo surgir como forma de resistência e audácia, embora nem sempre se possa ser sujeito, mas somente indivíduo. Para Touraine:

Só nos tornamos plenamente sujeitos quando aceitamos como nosso ideal reconhecer-nos - e fazer-nos reconhecer enquanto indivíduos - como seres individuados, que defendem e constroem sua singularidade, e dando, através de nossos atos de resistência, um sentido a nossa existência. (TOURAINE, 2006, p. 123).

Sob esta perspectiva, percebe-se que o sujeito é o imenso desejo de tornar-se ator, eis que o ator é social, e, por meio de suas açôes, pode transformar significativamente os espaços em que transita, e a partir do momento em que se compreende como ator, o sujeito se torna

5 Dados obtidos junto a Associação Nacional de Travestis e Transexuais-ANTRA.

6 Trata-se de um conjunto de normas que, historicamente, fazem da heterossexualidade uma espécie de monopólio da normalidade, estigmatizando e segregando os sujeitos que não vivem de acordo com tais normas, a exemplo das pessoas Trans. (LANZ, 2017). 
pleno, ou seja, ambos estão interligados (TOURAINE, 2004, p. 35). Mas, será que é simples ser permanentemente sujeito?

Ser sujeito, para o autor, é diuturnamente, transcender o que está posto, ou, ainda, ousa criar, resistir e mudar a realidade, é desejar tornar-se ator, já o ator, transcende este processo, e concretiza tais premissas. Ocorre que, em muitos casos, por interferências da sociedade (fator externo), este processo de tornar-se sujeito e/ou ator, é castrado. (TOURAINE, 2004, p. 34-35).

Logo, em relação às mulheres Trans, pode-se compreender que aquelas que estão marginalizadas e excluídas, podem, em algum momento da vida, possivelmente no seio familiar, (onde sofrem as primeiras rejeiçôes) sentirem-se culpadas e responsáveis por não se enquadrarem nos padróes sexualmente criados na sociedade, e neste sentido, tornam lento o caminho entre sujeito a ator (atriz) social.

Para Touraine, tais situaçóes trazem consigo uma espécie de vergonha a estas mulheres que, por diversas razóes, não buscaram se comportar como sujeitos, o que pode se dar pela dificuldade no processo de compreensão de cada uma como mulher Trans, e não há como culpalas por isso, na medida em que esta fragilidade pode em dado momento emancipa-las, acaso venha carregada de um desejo por mudança, ocasionando um rompimento com as amarras socialmente impostas. Ainda assim, estes processos paradoxais e carregados de historicidade no que se refere a constituição e transformação do sujeito, podem tanto afirmar novos sujeitos, como também os destruir (TOURAINE, 2004, p. 95-96).

Diz-se isso em razão de que, o universo Trans, diversas são as situaçóes enfrentadas no que diz respeito a privaçóes e preconceito, de modo que nem todos os lugares são para quem assim se reconhece. Prova disso são os inúmeros ataques a quem assim se identifica, bem como, a ausência destas pessoas junto ao mercado de trabalho, a espaços privados, educandários. É evidente que, o fato de não transitarem nestes locais não as torna inferiores, na medida em que nem sempre homens e mulheres Trans desejam neles se inserir. Ainda assim, pode que muitas mulheres Trans não vivenciem uma efetiva atuação social, imersas e presas a valores e práticas castradoras que a impedem de uma maior atuação como atrizes sociais.

Neste contexto, o caminhar de indivíduo e sujeito à ator/atriz social na seara Trans não é linear, haja vista as distintas realidades destas mulheres. "Só é ator quem se institui como sujeito de sua própria vida e seus atos" (TOURAINE, 2004, p. 108). Em relação às mulheres Trans, diante das inúmeras violaçóes a que são submetidas, este processo nem sempre se completa, de modo que muitas passam a vida atreladas ao status de indivíduo, apenas. $\mathrm{Na}$ visão touraineana, as mulheres Trans passariam ao status de atrizes sociais, na medida em que, por meio da coletividade, passassem a buscar seus direitos, ou, ainda, quando por meio de suas açóes impactassem outras vidas, a exemplo dos movimentos sociais, como o transfeminismo, que atua na busca por dignidade e cidadania em suas pautas, fazendo do coletivo, pulsão e força (TOURAINE, 2004, p. 98). Logo, só se torna ator aquele sujeito que não se permite ser castrado naquilo que deseja, e ousa emancipar-se (TOURAINE, 2004, p. 34-35).

$\mathrm{Na}$ realidade Trans, portanto, onde a estimativa de vida náo ultrapassa os 35 anos de idade, se torna assustador imaginar que muitas destas mulheres jamais chegarão ao status de sujeitas ou atrizes sociais, na medida em que a sociedade e suas práticas opressoras aniquilam suas existências antes deste processo de concluir. Urge, portanto, a necessidade de uma reeducação acerca de gênero, sexo e diversidade, a fim que as mulheres Trans sejam reconhecidas e respeitadas, 
podendo gozar de uma vida com dignidade e cidadania, realidade ainda distante na atualidade.

\section{Consideraçóes finais}

Rumando ao final deste ensaio, se pode compreender que os debates acerca de gênero, sexualidades, e, igualmente do universo Trans, ainda são alvo por valores morais, religiosos e sociais, o que torna lento qualquer avanço neste sentido. Urge, portanto, a necessidade da compreensão da pluralidade social em que estamos imersos, a fim de que se olhe o diferente como parte do todo, e como sujeito de direitos.

Não há mais como direcionar as pessoas gênero-divergentes um olhar patologizante e carregado de discriminação, o que muito é feito por meio da violência simbólica, mas, no mesmo passo, por formas de violência físicas, ocasionando muitas vezes mortes de quem assim se reconhece. Diz-se isso em razão de que, em meio à sociedade multicultural em que estamos imersos, não há mais como pensar que alguns grupos ou sujeitos possam dominar os demais, simplesmente por serem diferentes dos padrôes historicamente estabelecidos no que tange a sexualidade e a liberdade dos corpos e desejos. Não é possível, tampouco aceitável que os corpos e desejos dos indivíduos sejam castrados ou pré-determinados por outrem. Em uma sociedade multicultural, cabe o fomento a diversidade e à cidadania aos indivíduos que se percebem segregados ou julgados por seu modo de ser e existir no mundo.

Nesta perspectiva, fomentando a luta por emancipação Trans, os MS figuram como importante ferramenta de luta, na medida em que empoderam quem assim se reconhece na luta por reconhecimento e liberdade. Por meio de coletivos organizados, torna-se maior o alcance social neste sentido, de modo que os homens e mulheres Trans passam a não mais sentirem-se tão sozinhos em suas demandas e anseios. Neste sentido, acredita-se que o futurível Waratiano sinalize uma perspectiva de mudança desta realidade de segregação a este segmento, rumando para uma sociedade efetivamente plural e fraterna, onde os diferentes não sejam empurrados ao limbo social.

\section{Referências}

ANGELIN, Rosangela.Direitos humanos das mulheres e movimentos feministas nas sociedades multiculturais: uma leitura a partir da perspectiva teórica do reconhecimento e da redistribuição de gênero em Axel Honnet e Nancy Fraser. In: Anais do Congresso

Internacional da Faculdades EST. São Leopoldo: EST, v. 2, 2014. Disponível em: http:// anais.est.edu.br/index.php/congresso/article/view/248. Acesso em: 30 out. 2020.

BERTASO, João Martins. Cidadania, reconhecimento e solidariedade: sinais de uma fuga. In: Cidadania, diversidade e reconhecimento. Org. João Martins Bertaso. 2 Ed. Santo Ângelo, FURI, 2012. (p. 13-33).

CALDERONE, Mónica. Sobre Violencia Simbólica en Pierre Bourdieu. In: "La Trama de la Comunicación” Vol. 9, Anuario del Departamento de Ciencias de la Comunicación. Facultad de Ciencia Política y Relaciones Internacionales, Universidad Nacional de Rosario. Rosario. Argentina. UNR Editora, 2004.

HAN, Byung-Chul. Topologia da violência. Tradução de Enio Paulo Giachini. - Petrópolis, 
RJ: Vozes, 2017.

HONNETH, Axel. Luta por reconhecimento: a gramática moral dos conflitos sociais. Tradução de Luiz Repa. São Paulo: Ed. 34, 2003.

HONNETH, Axel; FRASER, Nancy. Redistribuition or recognition? A political-philosofical exchange. Tradução Joel Golb, James Ingram, Christiane Wilke. London; New Yourk: Verso, 2003.

HONNETH, Axel. Reificação: um estudo da teoria do reconhecimento. Traduzido por Rúrion Melo. São Paulo. Editora Unesp, 2018.

KOYAMA, Emi. The transfeminist manifesto. Eminism.org, 2001. Disponível em: http:// eminism.org/readings/pdf-rdg/tfmanifesto.pdf. Acesso em: 23 out. 2012

SÁNCHEZ, Davi Rubio. Encantos e desencantos dos direitos humanos: de emancipaçóes, libertaçôes e dominaçôes. Tradução Ivone Fernandes Morcilho Lixa, Helena Henkin. Porto Alegre. Editora Livraria do Advogado, 2014.

SANTOS, André Leonardo Copetti. LUCAS, Doglas Cesar. GHISLENI, Pâmela Copetti. Eros pede passagem: corpo, amor e desejo no direito contemporâneo. Rio de Janeiro. Editora Lumen Juris, 2019.

TOURAINE, Alain. KHOSROKHAVAR, Farhad. A busca de si: um diálogo sobre o sujeito. Tradução Caio Meira. Rio de Janeiro. Bertrand Brasil, 2004.

TOURAINE, A. El sujeto. Un nuevo paradigma para comprender el mundo de hoy. Buenos Aires: Paidós, 2006.

VERONESE, Marilia Veríssimo; LACERDA, Luiz Felipe Barboza. O sujeito e o indivíduo na perspectiva de Alain Touraine. In: Revista Soc. e Cult., Goiânia, v. 14, n. 2, p. 419-426, jul./ dez. 2011.

WARAT, Luis Alberto. Territórios desconhecidos: a procura surrealista pelos lugares do abandono do sentido e da reconstrução da subjetividade. Coordenadores: Orides Mezzaroba, Arno das Ri Júnior e outros. Florianópolis. Fundação Boiteux, 2004. 